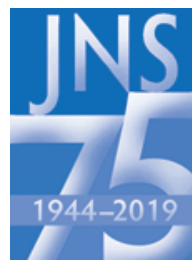

\title{
Abusive head trauma: evidence, obfuscation, and informed management
}

\author{
JNSPG 75th Anniversary Invited Review Article
}

Ann-Christine Duhaime, MD, ${ }^{1}$ and Cindy W. Christian, MD²

\begin{abstract}
1Department of Neurosurgery, Massachusetts General Hospital, Harvard Medical School, Boston, Massachusetts; and 2Department of Pediatrics, Children's Hospital of Philadelphia, The Perelman School of Medicine at the University of Pennsylvania, Philadelphia, Pennsylvania
\end{abstract}

\begin{abstract}
Abusive head trauma remains the major cause of serious head injury in infants and young children. A great deal of research has been undertaken to inform the recognition, evaluation, differential diagnosis, management, and legal interventions when children present with findings suggestive of inflicted injury. This paper reviews the evolution of current practices and controversies, both with respect to medical management and to etiological determination of the variable constellations of signs, symptoms, and radiological findings that characterize young injured children presenting for neurosurgical care.
\end{abstract}

https://thejns.org/doi/abs/10.3171/2019.7.PEDS18394

KEYWORDS child abuse; abusive head trauma; traumatic brain injury; subdural hematoma; nonaccidental trauma; shaken baby; infant

$\mathrm{N}$ ONACCIDENTAL trauma in infants and young children remains a common problem associated with unique challenges and intervention opportunities for neurosurgeons, other clinicians, child advocates, and legal professionals. Research has led to substantial progress in understanding the epidemiology, clinical presentation, evaluation, differential diagnosis, likely mechanisms, pathophysiology, management, legal issues, and outcomes of children with this constellation of injuries. This review seeks to update the reader on this sometimes-contentious topic and to provide practical guidance to clinicians faced with a patient for whom an inflicted injury is a consideration.

\section{Epidemiology}

Abusive head trauma (AHT) is a universal phenomenon, reported and studied around the world..$^{15,52,53}$ The incidence is estimated at 20-30/100,000 children, with victims' median age being 4 months, highlighting the vulnerability of young infants. More than 2000 hospitalized children are assigned diagnoses of AHT annually in the US using codebased definitions. ${ }^{73}$ Perpetrator confessions suggest that some infants are handled violently on multiple occasions prior to presenting for medical care, while others are injured in a single violent event. ${ }^{2}$

\section{Terminology and Mechanisms}

The terms "abusive head trauma," "nonaccidental trauma," and "inflicted injury" are used interchangeably to refer to cranial or nervous system injuries resulting from the deliberate application of force to a child. Identifying possible AHT prompts evaluation for additional injuries, involvement of child protection and law enforcement experts, and protecting the patient and other children from subsequent harm. ${ }^{61}$ Clinical, scientific, and policy approaches have evolved significantly since the mid-20th century ${ }^{4}$ (Fig. 1).

Clinical presentation, specific pathoanatomical injuries, and specific mechanisms vary among children with inflicted injuries, and the differential diagnosis includes accidental trauma and nontraumatic medical or congenital etiologies. It is the pattern and constellation of injuries in the context of the history and host (patient) factors that enable the clinician to make the determination of an inflicted 


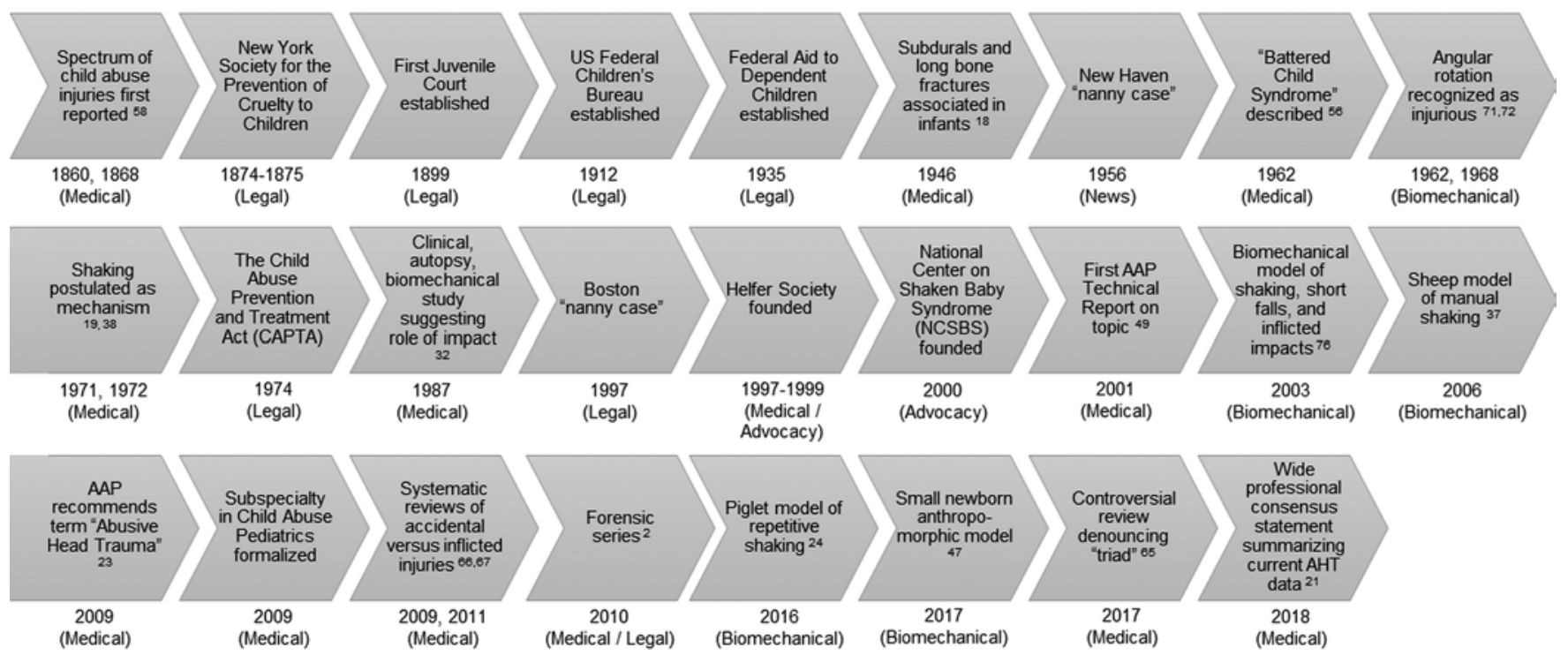

FIG. 1. Timeline showing evolution in recognition, advocacy, terminology, and biomechanics research of AHT. Additional information on other aspects is included in the text.

mechanism. This can be made with high confidence in some cases, while in others the data allow for suspicion but not a presumption of a nonaccidental cause..$^{30}$ As examples, subdural hemorrhage (SDH) with an acute skull fracture in an infant who is not yet rolling in the setting of exclusive caregivers who provide an unequivocal denial of any possible traumatic event, or acute SDH and skeletal injuries of various stages of healing in a child with a history of a 2-foot horizontal fall from a couch, are indicative of inflicted injury once medical conditions have been excluded. In other children, sufficient suspicions are raised that protection of the child is prioritized, even if the determination cannot be made definitively. Various reviews, algorithms, and decision rules have been created to assist the clinician in this determination, and child abuse specialists typically are familiar with these resources. ${ }^{30,43,51,54}$

Semantic differences between clinical and other disciplines exacerbate controversies in this arena. In medicine, a diagnosis typically refers to a pathoanatomical entity or pathophysiological process (e.g., subdural hematoma), while a mechanism is the mechanical cause of the injury (e.g., fall). Thus, AHT is not a "diagnosis" in the usual medical sense but instead refers to the determination of an inflicted mechanism to explain the findings (although there do exist "diagnostic codes" for inflicted injury). In forensics, proximate, intervening, and immediate causes refer to a chain of events resulting in death, and "mechanism" refers to the final fatal physiological derangemente.g., exsanguination. Thus, whether AHT is a diagnosis, cause, or mechanism depends on which meaning is being applied. For the ensuing discussion, we will use the term "mechanism" in the sense of mechanical forces.

Most head injury mechanisms include combinations of impact (contact) and inertial (intracranial motion) forces in varying magnitudes and directions. SDH is the most common pathoanatomical injury encountered in AHT and is associated with varying degrees of parenchymal brain injury, ranging from negligible through extensive..$^{27,45} \mathrm{On}$ CT scans, venous epidural collections can mimic SDH, causing further confusion. Acute SDH can occur from angular deceleration, from direct contact forces with cortical vessel tear, or from static strains such as parturition. While the exact forces required to cause SDH in infants of different ages remain incompletely understood, $\mathrm{SDH}$ associated with life-threatening parenchymal injury has rarely if ever been shown to be associated with simple falls from a horizontal position with head to ground distances under about 3 feet in otherwise healthy children. Mechanisms involving additional forces, such as falls from highchairs, children pushed from standing position, or falls from moving playground equipment rarely have been associated with more clinically significant or fatal injuries. $7,20,30,41,44,75$ The forces required to cause chronic or hemorrhagic CSF collections remain unclear and likely vary with conditions including large subarachnoid spaces or ventriculoperitoneal shunting.

Other injuries encountered in AHT include skull fractures, indicating impact, and scalp hematomas from impact or other strains such as delivery or hair pulling. Bilateral skull fractures can occur from a single frontal or occipital impact. The malleable head stopping against a soft surface widely distributes cranial contact forces that can remain below the threshold for visible external damage, despite brain deceleration reaching a high magnitude. . $^{32,76,79}$ It is thus a faulty assumption that the absence of physical or radiological signs of impact in a child with subdural hematoma implies impact did not occur and thereby confirms shaking.

Whether violent shaking alone can cause an SDH with severe brain injury or whether the large difference in force magnitude between shaking and impact (the latter up to 50 times greater than shaking) supports impact as the likely causative mechanism remains debated, in part because of the limitations of anthropomorphic or animal models to 
fully replicate the human situation. ${ }^{24,32,37,47,76}$ Nonetheless, inflicted impact forces are well within the range estimated to cause significant injury and are well above those generated by low-height falls. ${ }^{76}$ While low-height falls for infants can cause skull fractures and epidural hematomas, this mechanism is not associated with life-threatening primary brain injury. Cervical pathology seen on some autopsies and MRI studies suggests that shaking or impact hyperflexion may play a role in apnea or other clinical sequelae. ${ }^{48}$

Severe hemispheric damage can be bilateral or unilateral in AHT, countering the supposition that damage results solely from a uniform global insult such as hypoxia. ${ }^{27,31}$ Because of these variations in injury patterns, pediatric organizations have endorsed nonmechanistic terminology for this spectrum of injuries (AHT, nonaccidental trauma, inflicted injury), rather than the mechanistically narrow "shaken baby syndrome." 23 Despite controversies about shaking versus impact, children with certain constellations of head/brain and/or somatic injuries, in combination with a specific history or a lack of history, who have no predisposing medical condition, can be clearly determined to be the victims of inflicted injuries. Determination depends on the multiplicity and chronicity of injuries, constellations of injury that have not been shown to occur without mechanical trauma, or have not been reported in the large body of clinical series investigating specific types of accidental events.

\section{Clinical Presentation}

Clinical manifestations of AHT vary with age, mechanism, and specific types of injuries. Children present with variable neurological signs, from irritability to coma, with vomiting, seizures, or a bulging fontanelle or occasionally with occult injury identified as part of a child abuse evaluation for extracranial injuries. ${ }^{22}$ In at least half of AHT cases, there is no history of trauma, which can contribute to misdiagnosis; in the remainder, a low-height fall usually is described. $32,54,74$ Physician uncertainty and discomfort with child abuse can contribute to incorrect diagnosis. Up to one-third of AHT victims have evidence of a previous injury that was not recognized as inflicted, and they may subsequently suffer a more severe or even fatal injury. ${ }^{46,61,77}$ Racial disparities in evaluation of suspected abuse lead to both over- and underdiagnosis of AHT in different racial and socioeconomic populations. ${ }^{60}$

SDH is identified in most victims of AHT, and most SDHs in infants result from abuse. ${ }^{69}$ Serum biomarkers may help point to brain injury from any cause as a source of nonspecific symptoms in infants, but they are not yet widely available. ${ }^{16}$ Retinal hemorrhages that are bilateral, severe, and include posterior pole and peripheral hemorrhages are characteristic of AHT. ${ }^{17,68}$ Any bruising in nonambulatory infants should always raise the possibility of inflicted injury and is identified in about one-third of AHT patients. ${ }^{36,43,74}$

Up to half of patients have visible scalp bruising, which is less than that seen in accidental trauma. ${ }^{15,53,66,82}$ Neuroradiological imaging is unable to discriminate impact from nonimpact head injury; scalp hemorrhage may not be visible on the surface, and not all skull fractures result in identifiable scalp swelling. ${ }^{32,44,79}$

Fractures of various bones are found in approximately $18 \%-55 \%$ of young abused children, and about $25 \%$ of fractures in infants are attributable to abuse.9,62,64 Skull fractures are identified in approximately $25 \%$ of AHT victims, usually accompanied by intracranial injury.,74 No specific pattern of skull fracture discriminates an accidental from abusive mechanism, but multiple fractures, rib, spine and scapular fractures, and classic metaphyseal lesions are strong predictors of abuse when identified in infants with an intracranial injury. ${ }^{9,54,55,67,74}$ When patients present with combinations of characteristic findings, the probability of AHT can be estimated; for some combinations the positive predictive value approaches $100 \%$. $^{43,67,74}$

\section{Neurosurgical Assessment and Acute Management}

Neurosurgeons are consulted when history or findings suggest a traumatic injury to the head or spine, and they often play an important role in guiding appropriate neuroimaging and management. Attention to airway, breathing, and circulation is paramount, recognizing that young infants with skull fractures and scalp hemorrhages can suffer acute anemia and even shock. A trauma consult should be strongly considered to assess for occult injuries, including viscera.

It can be helpful to "create a mental video" by eliciting details of exactly what happened at the scene just before, during, and after the event. ${ }^{30}$ Where were the caregivers, and where was the child? What position was the child in before the fall, what was the head-to-ground height, point of contact, surface struck, and position after landing? Heights often can be measured from comparable furniture in the room in which the interview occurs. What happened immediately after injury through arriving at medical care? For mobile children, where and with whom was the child, and what brought the injury to attention? Similar detailed scenarios can be constructed when trauma is explicitly denied for events before and after symptoms were noted, and inconsistent or implausible histories identified. For admitted or witnessed assaults, a similarly detailed history can help estimate the types and magnitudes of forces experienced by the child.

Recognizing injury severity in infants with limited behavioral repertoires can be challenging, and subtle seizures can be misinterpreted as spontaneous movements. The absence of crying or grimacing to painful stimulation, even if the eyes are open, is highly suggestive of serious brain dysfunction in injured infants. ${ }^{33}$

The neurosurgeon determines whether intracranial hemorrhages require evacuation and which surgical procedure to use. For infants with an open fontanelle, bloody fluid, and signs of increased intracranial pressure or cortical irritation, drainage via a fontanelle tap or subdural drain is an option and confirms the presence of blood in equivocal situations. In cases of more solid clots with mass effect, surgical decisions follow similar principles as those for older children, to prevent herniation and preserve uninjured brain. In children with unilateral pan-hemispheric 

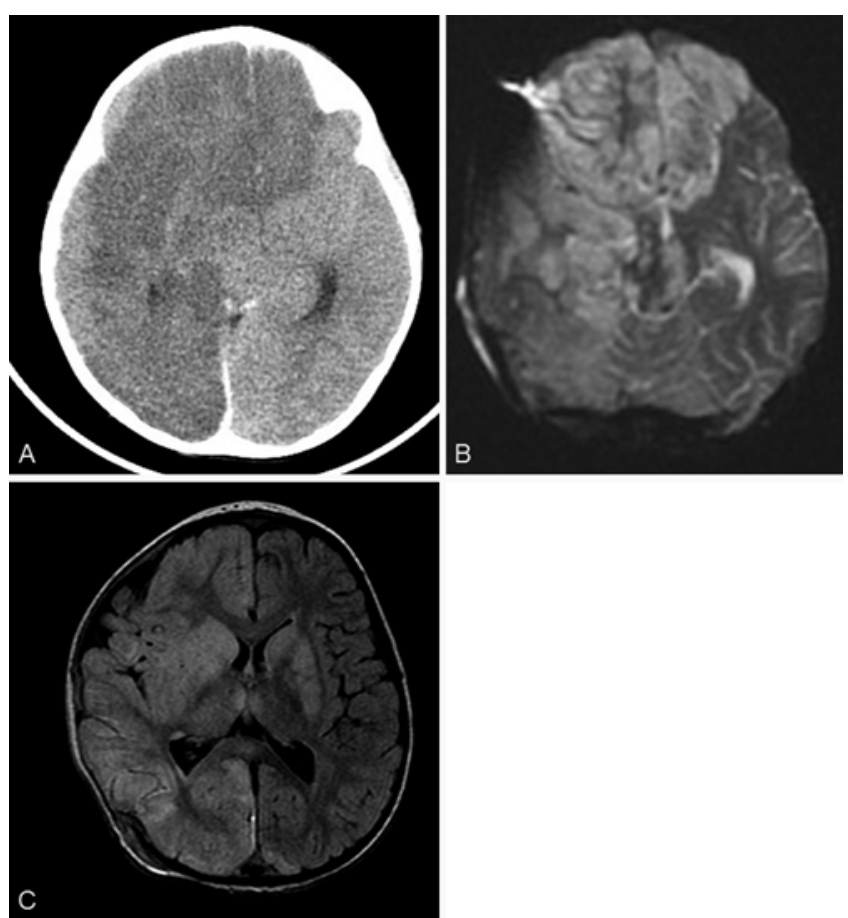

FIG. 2. Radiological findings showing unilateral pan-hemispheric damage patterns associated with AHT. A: Axial brain CT scan of an unresponsive 2-year-old beaten by caregiver on the previous night. Note small right subdural collection and extensive brain swelling. B: Diffusionweighted MR image of same child showing abnormal signal and swelling of entire involved hemisphere, along with contralateral subfalcine herniation and frontal infarction. C: Axial FLAIR MR image of 1-year-old child presenting with coma, right extensor posturing, and dilated right pupil, scanned after early evacuation of subdural hematoma and hemicraniectomy. Midline shift resolved; note sparing of contralateral frontal lobe.

damage, early surgery can prevent subfalcine herniation and contralateral frontal infarction (Fig. 2), even if the natural history of the ipsilateral hemisphere remains unaltered. While potentially beneficial, hemicraniectomy is associated with a high rate of hydrocephalus requiring shunt placement and cranial complications, including bone resorption, which can be challenging to manage in young children. ${ }^{1,70}$

Two-thirds of children with an acute inflicted injury have seizures, with many being subclinical. Thus, some centers treat all children with prophylactic anticonvulsant agents and employ continuous EEG monitoring for children with more severe injuries..$^{10,14,29,40,63}$ Early seizures correlate with poor outcome and may contribute to the pathophysiology of the injury. ${ }^{25,29}$ Monitoring and treatment of intracranial pressure vary among institutions; some practitioners feel that infants with open fontanelles can be followed clinically, while seriously injured toddlers are managed more like older children, but definitive data remain sparse on efficacy. ${ }^{57}$ Children with inflicted injuries who do not have serious brain injuries are managed for presenting problems by appropriate specialists.

\section{Radiology}

CT scanning has been the historical mainstay of the ra- diological diagnosis of head trauma, but MRI has gained traction due to improved sensitivity for certain injury types, shorter scan techniques allowing unsedated imaging, absence of radiation, and increasing availability. ${ }^{48,81}$ CT scanning is superior for fracture detection, and MRI is more sensitive for parenchymal hemorrhage and contusion, distinguishing the subdural from subarachnoid compartments, and demonstrating ischemic changes, typically using T2-weighted, susceptibility, and diffusion-weighted sequences. The latter may be the earliest means of detecting so-called big black brain or hemispheric hypodensity, terms based on CT findings, but perhaps more universally described as profound pan-hemispheric damage. Neither CT nor MRI can precisely "date" a hemorrhage beyond some general estimates. Likewise, blood of different densities or intensities does not necessarily connote "old" and "new" or repetitive injuries, because of mixing of blood products in the subdural and subarachnoid spaces., ${ }^{3,78} \mathrm{Be}-$ cause of the superior sensitivity and prognostic value of MRI and its ability to assess cervical ligamentous injury, some centers prioritize MRI for head and spine imaging and utilize skull radiographs or reduced-radiation 3D skull CT to assess for fractures. More detailed vascular imaging with CT or MR angiography or venography is sometimes indicated to assess for venous sinus thrombosis, arteriovenous malformation or fistula, aneurysm, and arterial dissection. ${ }^{83}$

High-quality skeletal survey following published guidelines (https://www.acr.org/-/media/ACR/Files/PracticeParameters/Skeletal-Survey.pdf) is an essential component of the evaluation of patients with a suspected AHT, as the identification of unexplained fractures in this setting strongly supports a diagnosis of trauma and abuse. Repeating the skeletal survey 2-3 weeks after initial presentation identifies fractures that were previously not visible radiographically (e.g., rib fractures and classic metaphyseal lesions), assists in dating of the injury, and improves the diagnostic sensitivity and specificity of the study.9,39 Abdominal imaging is indicated for children with notable abnormalities in their abdominal trauma laboratory testing or for those with external evidence of abdominal injury.

\section{Medical Evaluation}

Infants and children who present with unexplained alteration in mental status or injury require careful consideration for the possibility of abuse. Building on the findings at presentation, tailored medical evaluation helps guide management and elucidate potential contributors to the clinical picture. The initial laboratory assessment screens for underlying treatable diseases that cause intracranial hemorrhage, as well as hematological and metabolic consequences of brain injury. Patients with primary coagulopathies such as hemophilia or liver disease that impairs vitamin $\mathrm{K}$ production can present with intracranial hemorrhage. ${ }^{6}$ Brain tissue procoagulant release causing coagulopathy is a well-documented consequence of traumatic brain injury, including AHT.42,84 Hepatic enzymes may be elevated from abdominal trauma, transient ischemic liver injury, or undiagnosed primary liver disease. ${ }^{59}$ Standard measures of coagulation, electrolytes, 
and abdominal trauma laboratory tests are recommended for all patients with AHT, and guidelines are available through the American Academy of Pediatrics (https:// pediatrics.aappublications.org/content/135/5/e1337?utm_ medium=referral\&utm_source=r360; https://pediatrics. aappublications.org/content/131/4/e1314.long). ${ }^{5,22}$

For many children, the diagnosis of AHT is readily evident by the range of injuries identified during the evaluation, but for others, careful consideration of alternative diseases requires additional evaluation. The differential diagnosis of SDH in infants and children includes birth and accidental trauma; metabolic and genetic diseases; hematological, oncological, and autoimmune diseases; congenital malformations; and others. ${ }^{22}$ Likewise, many pediatric diseases predispose to retinal hemorrhages, bruises, or fractures in infants and young children. Attention to details in the history, physical examination, laboratory tests, and radiological images guides the medical evaluation, as it does with all diagnoses. Special attention should be given to children who present to care very early in infancy (when metabolic and genetic diseases may become symptomatic), children with unusual histories or physical findings, children with multisystem chronic diseases, and children whose laboratory evaluation reveals atypical results. Because accidental head trauma occasionally can result in severe neurological injury, an open mind and thorough, objective assessment of all children who are evaluated for possible AHT is mandatory. 7,20

The medical evaluation would not be complete without a thorough psychosocial assessment and collaboration with hospital social workers, who serve as liaisons with Child Protective Services (CPS) and law enforcement. Social work and, if available, the hospital's Child Protection Team should be consulted as early as possible to assist with diagnostic evaluation, mandatory reporting, and family support.

\section{Controversy, Challenge, and Opportunity}

Contention surrounding the diagnosis of AHT, and most specifically the concept of shaken baby syndrome (SBS), has emerged over the past 2 decades, having primarily been debated in the courtroom. Although medical skepticism and scientific debate are important to advance medical knowledge and improve patient treatment and public health prevention, because the civil and criminal justice systems are often involved in cases of AHT, scientific debate related to AHT is often argued during legal proceedings rather than in medical journals, a system not designed to determine scientific truth.

As an example, in recent years, a case report of unique medical causation involving choking has been proffered in courts as an alternative explanation for AHT, despite criticisms of intentional omissions and misrepresentations..$^{12,34}$ Recently, systematic reviews highlighting the injuries associated with AHT, as well as systematic reviews arguing against the diagnosis of SBS, have been published. ${ }^{35,65,66,74}$ Some of these reviews have been sharply criticized for improper methodology, provoking intense debate. ${ }^{26}$

Recent arguments against the validity of AHT/SBS have focused on the specificity of a triad of SDH, retinal hemorrhage, and encephalopathy that is claimed to be diagnostic of AHT. This controversy regarding a triad is, in fact, an oversimplification, created for legal defense arguments against the determination of AHT. ${ }^{26}$ The pediatric and child abuse communities agree that the so-called triad is not diagnostic of AHT. The findings of SDH, retinal hemorrhage, and encephalopathy, while commonly identified in victims of AHT and characteristic of abuse, are not diagnostic of such, and there are known diseases and other medical conditions that are considered in the clinical differential diagnosis. In all cases, a determination of AHT requires careful consideration of all clinical facts. The findings should be considered in the appropriate clinical context, and a rush to determination of abuse is never appropriate. As noted above, for some children, the constellation of injuries in the context of their history makes a clear determination, and in others identification of additional injuries confirms the mechanism of injury and child abuse. Additional investigation by law enforcement or CPS sometimes uncovers information that supports or refutes accidental or abusive injury. In some instances, no clear determination can be made. In other cases, known medical diseases are identified, and abuse is eliminated from consideration.

Published peer-reviewed medical literature regarding AHT is extensive, and clinical experience by thousands of physicians leaves no doubt that infants and young children can sustain head and brain injury by those who are entrusted to care for them. There are many ways to cause inflicted injury, and there is much still to learn about the infant brain, its response to trauma, the pathophysiology of the often extensive damage seen, and approaches for early detection and prevention of abuse. Some injuries are accidental and some remain appropriately indeterminate with respect to abuse. Nevertheless, to deny the existence of AHT by employing unique alternative theories of causation, faulty mathematical analyses, selective biomechanical data, and absolute intolerance for the limitations of clinical research is an unreasonably narrow response to an accumulated body of clinical and scientific evidence.

\section{Legal Interventions}

Federal and state laws define child abuse, and civil and criminal responses to abuse are generally guided by state statutes. CPS are civil agencies established to investigate reports of maltreatment, ensure the ongoing safety of children, and work with families who require support and intervention; potential crimes are investigated by law enforcement. Most cases of AHT involve investigations by both CPS and law enforcement. Physicians are legally mandated to report suspected abuse, with reporting mechanisms varying by state. Reporting requires a reasonable suspicion of abuse, not a certainty. Victims of AHT require protection and family intervention, sometimes requiring the removal of a suspected perpetrator from the home or the temporary placement of the patient in kinship or foster care. Decisions made by CPS may be guided by medical team input. State laws protect physicians if a suspicion proves erroneous as long as the report was made in good faith, and physicians can be held responsible in both civil 
and criminal courts for failing to report suspicions. Physicians may be subpoenaed to testify in civil hearings and criminal trials to help educate the court regarding medically related issues. Although physicians often loathe the adversarial nature of the courtroom, objective, honest testimony is vital to the court's ability to render justice.

\section{Outcomes and Prevention}

Neurological and functional outcomes in children with inflicted injuries are variable, but generally are worse than for children with accidental mechanisms. Cognitive and behavioral problems, as well as spasticity, hemiparesis, and epilepsy are common, and of children who survive, about two thirds are severely or moderately disabled, and one-third have relatively good outcomes, though they may have cognitive or behavioral deficits. ${ }^{11,36}$

Despite laudable efforts, prevention of AHT has proven elusive. Programs to improve awareness of AHT, normalize infant crying and appropriate parental coping, and educate parents of newborns about the dangers of shaking and other violent actions have been shown to increase knowledge of the problem, but have not been translated into substantial reductions in AHT incidence. ${ }^{13,28,50}$ Recognition of those most likely to inflict abuse has helped target education efforts (fathers/stepfathers/boyfriends then babysitters then mothers) ${ }^{80}$ Increased physician recognition of the significance of common antecedent injuries may facilitate appropriate interventions that would prevent subsequent serious injury. ${ }^{77}$

\section{Conclusions}

Neurosurgeons have an important role to play in the evaluation, management, and understanding of AHT. While controversies remain and will require ongoing study, that inflicted injury occurs is unequivocal. Equally clear is that in some cases, while suspicion exists, a definitive determination of an inflicted mechanism cannot be made with certainty, and then protection of the child becomes paramount. Management relies on the basic principles of pediatric neurotrauma care, with the recognition that although young children can be more difficult to assess, appropriate surgical intervention, seizure management, and critical care can be brain sparing. Collaborating with child abuse specialists to help come to a determination of how the injuries occurred is another part of the neurosurgeon's contribution to the care of young children with neurotrauma.

\section{References}

1. Adamo MA, Drazin D, Waldman JB: Decompressive craniectomy and postoperative complication management in infants and toddlers with severe traumatic brain injuries. J Neurosurg Pediatr 3:334-339, 2009

2. Adamsbaum C, Grabar S, Mejean N, Rey-Salmon C: Abusive head trauma: judicial admissions highlight violent and repetitive shaking. Pediatrics 126:546-555, 2010

3. Adamsbaum C, Morel B, Ducot B, Antoni G, Rey-Salmon $\mathrm{C}$ : Dating the abusive head trauma episode and perpetrator statements: key points for imaging. Pediatr Radiol 44 (Suppl 4):S578-S588, 2014

4. Al-Holou WN, O'Hara EA, Cohen-Gadol AA, Maher CO:
Nonaccidental head injury in children. Historical vignette. J

Neurosurg Pediatr 3:474-483, 2009

5. Anderst JD, Carpenter SL, Abshire TC: Evaluation for bleeding disorders in suspected child abuse. Pediatrics 131:e1314-e1322, 2013

6. Anderst JD, Carpenter SL, Presley R, Berkoff MC, Wheeler AP, Sidonio RF Jr, et al: Relevance of abusive head trauma to intracranial hemorrhages and bleeding disorders. Pediatrics 141:e20173485, 2018

7. Atkinson N, van Rijn RR, Starling SP: Childhood falls with occipital impacts. Pediatr Emerg Care 34:837-841, 2018

8. Barber I, Kleinman PK: Imaging of skeletal injuries associated with abusive head trauma. Pediatr Radiol 44 (Suppl 4):S613-S620, 2014

9. Barber I, Perez-Rossello JM, Wilson CR, Kleinman PK: The yield of high-detail radiographic skeletal surveys in suspected infant abuse. Pediatr Radiol 45:69-80, 2015

10. Barlow KM, Spowart JJ, Minns RA: Early posttraumatic seizures in non-accidental head injury: relation to outcome. Dev Med Child Neurol 42:591-594, 2000

11. Barlow KM, Thomson E, Johnson D, Minns RA: Late neurologic and cognitive sequelae of inflicted traumatic brain injury in infancy. Pediatrics 116:e174-e185, 2005

12. Barnes PD, Galaznik J, Gardner H, Shuman M: Infant acute life-threatening event-dysphagic choking versus nonaccidental injury. Semin Pediatr Neurol 17:7-11, 2010

13. Barr RG, Rivara FP, Barr M, Cummings P, Taylor J, Lengua LJ, et al: Effectiveness of educational materials designed to change knowledge and behaviors regarding crying and shaken-baby syndrome in mothers of newborns: a randomized, controlled trial. Pediatrics 123:972-980, 2009

14. Bechtel K, Stoessel K, Leventhal JM, Ogle E, Teague B, Lavietes S, et al: Characteristics that distinguish accidental from abusive injury in hospitalized young children with head trauma. Pediatrics 114:165-168, 2004

15. Bennett S, Ward M, Moreau K, Fortin G, King J, Mackay M, et al: Head injury secondary to suspected child maltreatment: results of a prospective Canadian national surveillance program. Child Abuse Negl 35:930-936, 2011

16. Berger RP, Pak BJ, Kolesnikova MD, Fromkin J, Saladino $\mathrm{R}$, Herman BE, et al: Derivation and validation of a serum biomarker panel to identify infants with acute intracranial hemorrhage. JAMA Pediatr 171:e170429, 2017

17. Binenbaum G, Mirza-George N, Christian CW, Forbes BJ: Odds of abuse associated with retinal hemorrhages in children suspected of child abuse. J AAPOS 13:268-272, 2009

18. Caffey J: Multiple fractures in long bones in infants suffering from chronic subdural hematoma. Am J Roentgenol 56:163-173, 1946

19. Caffey J: On the theory and practice of shaking infants: its potential residual effects of permanent brain damage and mental retardation. Am J Dis Child 124:161-169, 1972

20. Chadwick DL, Bertocci G, Castillo E, Frasier L, Guenther E, Hansen K, et al: Annual risk of death resulting from short falls among young children: less than 1 in 1 million. Pediatrics 121:1213-1224, 2008

21. Choudhary AK, Servaes S, Slovis TL, Palusci VJ, Hedlund GL, Narang SK, et al: Consensus statement on abusive head trauma in infants and young children. Pediatr Radiol 48:1048-1065, 2018

22. Christian CW: The evaluation of suspected child physical abuse. Pediatrics 135:e1337-e1354, 2015

23. Christian CW, Block R: Abusive head trauma in infants and children. Pediatrics 123:1409-1411, 2009

24. Coats B, Binenbaum G, Smith C, Peiffer RL, Christian $\mathrm{CW}$, Duhaime AC, et al: Cyclic head rotations produce modest brain injury in infant piglets. J Neurotrauma 34:235-247, 2017

25. Costine-Bartell BA, McGuone D, Price G, Crawford E, 
Keeley KL, Munoz-Pareja J, et al: Development of a model of hemispheric hypodensity ("big black brain"). J Neurotrauma 36:815-833, 2019

26. Debelle GD, Maguire S, Watts P, Nieto Hernandez R, Kemp AM: Abusive head trauma and the triad: a critique on behalf of RCPCH of 'Traumatic shaking: the role of the triad in medical investigations of suspected traumatic shaking'. Arch Dis Child 103:606-610, 2018

27. Dias MS, Backstrom J, Falk M, Li V: Serial radiography in the infant shaken impact syndrome. Pediatr Neurosurg 29:77-85, 1998

28. Dias MS, Rottmund CM, Cappos KM, Reed ME, Wang M, Stetter C, et al: Association of a postnatal parent education program for abusive head trauma with subsequent pediatric abusive head trauma hospitalization rates. JAMA Pediatr 171:223-229, 2017

29. Dingman AL, Stence NV, O'Neill BR, Sillau SH, Chapman KE: Seizure severity is correlated with severity of hypoxicischemic injury in abusive head trauma. Pediatr Neurol 82:29-35, 2018

30. Duhaime AC, Alario AJ, Lewander WJ, Schut L, Sutton LN, Seidl TS, et al: Head injury in very young children: mechanisms, injury types, and ophthalmologic findings in 100 hospitalized patients younger than 2 years of age. Pediatrics 90:179-185, 1992

31. Duhaime AC, Durham SR: Traumatic brain injury in infants: the phenomenon of subdural hemorrhage with hemispheric hypodensity ("big black brain"). Prog Brain Res 161:293302, 2007

32. Duhaime AC, Gennarelli TA, Thibault LE, Bruce DA, Margulies SS, Wiser R: The shaken baby syndrome. A clinical, pathological, and biomechanical study. J Neurosurg 66:409-415, 1987

33. Durham SR, Clancy RR, Leuthardt E, Sun P, Kamerling S, Dominguez T, et al: CHOP Infant Coma Scale ("Infant Face Scale"): a novel coma scale for children less than two years of age. J Neurotrauma 17:729-737, 2000

34. Edwards GA: Mimics of child abuse: can choking explain abusive head trauma? J Forensic Leg Med 35:33-37, 2015

35. Elinder G, Eriksson A, Hallberg B, Lynøe N, Sundgren PM, Rosén M, et al: Traumatic shaking: the role of the triad in medical investigations of suspected traumatic shaking. Acta Paediatr 107 (Suppl 472):3-23, 2018

36. Fanconi M, Lips U: Shaken baby syndrome in Switzerland: results of a prospective follow-up study, 2002-2007. Eur J Pediatr 169:1023-1028, 2010

37. Finnie JW, Blumbergs PC, Manavis J, Turner RJ, Helps S, Vink R, et al: Neuropathological changes in a lamb model of non-accidental head injury (the shaken baby syndrome). J Clin Neurosci 19:1159-1164, 2012

38. Guthkelch AN: Infantile subdural hematoma and its relationship to whiplash injuries. Br Medical J 2:430-431, 1971

39. Harper NS, Lewis T, Eddleman S, Lindberg DM: Followup skeletal survey use by child abuse pediatricians. Child Abuse Negl 51:336-342, 2016

40. Hasbani DM, Topjian AA, Friess SH, Kilbaugh TJ, Berg RA, Christian CW, et al: Nonconvulsive electrographic seizures are common in children with abusive head trauma. Pediatr Crit Care Med 14:709-715, 2013

41. Hughes J, Maguire S, Jones M, Theobald P, Kemp A: Biomechanical characteristics of head injuries from falls in children younger than 48 months. Arch Dis Child 101:310-315, 2016

42. Hymel KP, Abshire TC, Luckey DW, Jenny C: Coagulopathy in pediatric abusive head trauma. Pediatrics 99:371-375, 1997

43. Hymel KP, Wang M, Chinchilli VM, Karst WA, Willson DF, Dias MS, et al: Estimating the probability of abusive head trauma after abuse evaluation. Child Abuse Negl 88:266274,2019
44. Ibrahim NG, Wood J, Margulies SS, Christian CW: Influence of age and fall type on head injuries in infants and toddlers. Int J Dev Neurosci 30:201-206, 2012

45. Ichord RN, Naim M, Pollock AN, Nance ML, Margulies SS, Christian CW: Hypoxic-ischemic injury complicates inflicted and accidental traumatic brain injury in young children: the role of diffusion-weighted imaging. J Neurotrauma 24:106118,2007

46. Jenny C, Hymel KP, Ritzen A, Reinert SE, Hay TC: Analysis of missed cases of abusive head trauma. JAMA 281:621626, 1999

47. Jenny CA, Bertocci G, Fukuda T, Rangarajan N, Shams T: Biomechanical response of the infant head to shaking: an experimental investigation. J Neurotrauma 34:1579-1588, 2017

48. Kadom N, Khademian Z, Vezina G, Shalaby-Rana E, Rice A, Hinds T: Usefulness of MRI detection of cervical spine and brain injuries in the evaluation of abusive head trauma. Pediatr Radiol 44:839-848, 2014

49. Kairys S, Alexander R, Block R, Everett V: Shaken baby syndrome: rotational cranial injuries - technical report. Pediatrics 108:206-210, 2001

50. Keenan HT, Leventhal JM: A case-control study to evaluate Utah's shaken baby prevention program. Acad Pediatr 10:389-394, 2010

51. Keenan HT, Runyan DK, Marshall SW, Nocera MA, Merten DF: A population-based comparison of clinical and outcome characteristics of young children with serious inflicted and noninflicted traumatic brain injury. Pediatrics 114:633-639, 2004

52. Keenan HT, Runyan DK, Marshall SW, Nocera MA, Merten DF, Sinal SH: A population-based study of inflicted traumatic brain injury in young children. JAMA 290:621-626, 2003

53. Kelly P, Farrant B: Shaken baby syndrome in New Zealand, 2000-2002. J Paediatr Child Health 44:99-107, 2008

54. Kelly P, John S, Vincent AL, Reed P: Abusive head trauma and accidental head injury: a 20 -year comparative study of referrals to a hospital child protection team. Arch Dis Child 100:1123-1130, 2015

55. Kemp AM, Dunstan F, Harrison S, Morris S, Mann M, Rolfe $\mathrm{K}$, et al: Patterns of skeletal fractures in child abuse: systematic review. BMJ 337:a1518, 2008

56. Kempe CH, Silverman FN, Steele BF, Droegmueller W, Silver HK: The battered-child syndrome. JAMA 181:105-112, 1962

57. Kochanek PM, Tasker RC, Carney N, Totten AM, Adelson PD, Selden NR, et al: Guidelines for the Management of Pediatric Severe Traumatic Brain Injury, Third Edition: update of the Brain Trauma Foundation guidelines, executive summary. Neurosurgery 84:1169-1178, 2019

58. Labbe J: Ambroise Tardieu: the man and his work on child maltreatment a century before Kempe. Child Abuse Negl 29:311-324, 2005

59. Lane WG, Dubowitz H, Langenberg P: Screening for occult abdominal trauma in children with suspected physical abuse. Pediatrics 124:1595-1602, 2009

60. Lane WG, Rubin DM, Monteith R, Christian CW: Racial differences in the evaluation of pediatric fractures for physical abuse. JAMA 288:1603-1609, 2002

61. Letson MM, Cooper JN, Deans KJ, Scribano PV, Makoroff KL, Feldman KW, et al: Prior opportunities to identify abuse in children with abusive head trauma. Child Abuse Negl 60:36-45, 2016

62. Leventhal JM, Martin KD, Asnes AG: Incidence of fractures attributable to abuse in young hospitalized children: results from analysis of a United States database. Pediatrics 122:599-604, 2008

63. Liesemer K, Bratton SL, Zebrack CM, Brockmeyer D, Statler KD: Early post-traumatic seizures in moderate to severe pe- 
diatric traumatic brain injury: rates, risk factors, and clinical features. J Neurotrauma 28:755-762, 2011

64. Lindberg DM, Berger RP, Reynolds MS, Alwan RM, Harper NS: Yield of skeletal survey by age in children referred to abuse specialists. J Pediatr 164:1268-1273, 1273.e1, 2014

65. Lynøe N, Elinder G, Hallberg B, Rosén M, Sundgren P, Eriksson A: Insufficient evidence for 'shaken baby syndrome'a systematic review. Acta Paediatr 106:1021-1027, 2017

66. Maguire S, Pickerd N, Farewell D, Mann M, Tempest V, Kemp AM: Which clinical features distinguish inflicted from non-inflicted brain injury? A systematic review. Arch Dis Child 94:860-867, 2009

67. Maguire SA, Kemp AM, Lumb RC, Farewell DM: Estimating the probability of abusive head trauma: a pooled analysis. Pediatrics 128: 550-e564, 2011

68. Maguire SA, Watts PO, Shaw AD, Holden S, Taylor RH, Watkins WJ, et al: Retinal haemorrhages and related findings in abusive and non-abusive head trauma: a systematic review. Eye (Lond) 27:28-36, 2013

69. Matschke J, Voss J, Obi N, Görndt J, Sperhake JP, Püschel K, et al: Nonaccidental head injury is the most common cause of subdural bleeding in infants $<1$ year of age. Pediatrics 124:1587-1594, 2009

70. Oluigbo CO, Wilkinson CC, Stence NV, Fenton LZ, McNatt SA, Handler MH: Comparison of outcomes following decompressive craniectomy in children with accidental and nonaccidental blunt cranial trauma. J Neurosurg Pediatr 9:125-132, 2012

71. Ommaya AK, Faas F, Yarnell P: Whiplash injury and brain damage: an experimental study. JAMA 204:285-289, 1968

72. Ommaya AK, Yarnell P: Subdural hematoma after whiplash injury. Lancet 2:237-239, 1962

73. Parks S, Sugerman D, Xu L, Coronado V: Characteristics of non-fatal abusive head trauma among children in the USA, 2003-2008: application of the CDC operational case definition to national hospital inpatient data. Inj Prev 18:392-398, 2012

74. Piteau SJ, Ward MG, Barrowman NJ, Plint AC: Clinical and radiographic characteristics associated with abusive and nonabusive head trauma: a systematic review. Pediatrics 130:315-323, 2012

75. Plunkett J: Fatal pediatric head injuries caused by shortdistance falls. Am J Forensic Med Pathol 22:1-12, 2001

76. Prange MT, Coats B, Duhaime AC, Margulies SS: Anthropomorphic simulations of falls, shakes, and inflicted impacts in infants. J Neurosurg 99:143-150, 2003

77. Sheets LK, Leach ME, Koszewski IJ, Lessmeier AM, Nugent
M, Simpson P: Sentinel injuries in infants evaluated for child physical abuse. Pediatrics 131:701-707, 2013

78. Sieswerda-Hoogendoorn T, Postema FAM, Verbaan D, Majoie CB, van Rijn RR: Age determination of subdural hematomas with CT and MRI: a systematic review. Eur J Radiol 83:1257-1268, 2014

79. Sieswerda-Hoogendoorn T, Robben SG, Karst WA, Moesker FM, van Aalderen WM, Laméris JS, et al: Abusive head trauma: differentiation between impact and non-impact cases based on neuroimaging findings and skeletal surveys. Eur J Radiol 83:584-588, 2014

80. Starling SP, Holden JR, Jenny C: Abusive head trauma: the relationship of perpetrators to their victims. Pediatrics 95:259-262, 1995

81. Vázquez E, Delgado I, Sánchez-Montañez A, Fábrega A, Cano P, Martín N: Imaging abusive head trauma: why use both computed tomography and magnetic resonance imaging? Pediatr Radiol 44 (Suppl 4):S589-S603, 2014

82. Vinchon M, de Foort-Dhellemmes S, Desurmont M, Delestret I: Confessed abuse versus witnessed accidents in infants: comparison of clinical, radiological, and ophthalmological data in corroborated cases. Childs Nerv Syst 26:637-645, 2010

83. Young JY, Duhaime AC, Caruso PA, Rincon SP: Comparison of non-sedated brain MRI and CT for the detection of acute traumatic injury in children 6 years of age or less. Emerg Radiol 23:325-331, 2016

84. Zhang J, Jiang R, Liu L, Watkins T, Zhang F, Dong JF: Traumatic brain injury-associated coagulopathy. J Neurotrauma 29:2597-2605, 2012

\section{Disclosures}

Dr. Christian reports that she provides medical legal expert work in child abuse.

\section{Author Contributions}

Conception and design: both authors. Analysis and interpretation of data: both authors. Drafting the article: both authors. Critically revising the article: both authors. Reviewed submitted version of manuscript: both authors.

\section{Correspondence}

Ann-Christine Duhaime: Massachusetts General Hospital, Boston, MA. aduhaime@mgh.harvard.edu. 